\title{
Thinking Like an Engineer: Responding to the Engineering Blind Spot at Liberal Arts Colleges
}

\section{Prof. Daniel Flath, Macalester College}

Dan Flath, with MS in Electrical Engineering and $\mathrm{PhD}$ in mathematics, is a mathematics professor long interested in curricular reform in mathematics. He has co-authored an innovative calculus textbook and worked on modeling based reform of differential equations courses. He is currently working to create an engineering presence for all students in a liberal arts college environment with no engineering program.

\section{Prof. Diane P Michelfelder, Macalester College}

Diane P. Michelfelder is Professor of Philosophy at Macalester College. Her primary areas of research inquiry are the philosophy of technology and the philosophy of engineering. She has been actively involved in the creation and development of fPET: the Forum on Philosophy, Engineering, and Technology, and has served as the president of the Society for Philosophy and Technology. Currently, she is co-editor-in-chief of that society's journal, Techné: Research in Philosophy and Technology. 


\section{Thinking Like an Engineer: Responding to the Engineering Blind Spot at Liberal Arts Colleges}

Part One: introduction

Among the many thoughtful and compelling observations made by James Duderstadt in his 2010 essay "Engineering for a Changing World", collected in Dominico Grasso's and Melody Brown Burkins' Holistic Engineering Education: Beyond Technology, we find this: "Today we have a society profoundly dependent upon technology, profoundly dependent on engineers who produce that technology, and profoundly ignorant of technology" (p.31). Such profound ignorance reveals a profound social need. Writes Duderstadt: "Perhaps the most urgent need of our society is a deeper understanding and appreciation for technology on the part of all college graduates rather than only those seeking engineering degrees" (p.21), and also proposes that the study of engineering or technology be included under the umbrella of liberal arts disciplines (p.31).

The point that now is the moment to expand the idea of the liberal arts to see engineering as a liberal art as a liberal art is deftly developed by Carol T. Christ in another paper collected in this same volume (Christ, 2010). Emphasizing how what counts as a discipline within the liberal arts has, from Jefferson's day onwards, been a fairly fluid notion, she argues that now is the moment to expand the liberal arts to include engineering, particularly given the overlap between the approach that engineers need to take to solve problems and how problems are solved in other disciplines, and the fact that the knowledge to solve these problems is interdisciplinary in scope, using "a broad range of knowledge in science and mathematics to develop engineering solutions within a social, political, economic, and aesthetic context" (p.78).

Despite these and similar ideas subsequently expressed by others (cf. for example Bucciarelli and Drew, 2015), it is safe to say that there has not exactly been a rush among liberal arts colleges to include engineering as a member of the curricular club. This is understandable with respect to developing undergraduate majors in the field, given the high costs of mounting and maintaining such programs. But what about individual courses - courses designed to introduce liberal arts undergraduate students to the increasingly engineered world in which they will go on to have careers, most in fields other than engineering? While there are some notable exceptions, including Smith College's "Engineering for Everyone" course, Wellesley's "Making a Difference Through Engineering" and Hope College's "Science and Technology in Everyday Life" (see the "Engineering-Enhanced Liberal Education Project" on the ASEE website for additional detail), courses focused on engineering and the engineered world and accessible to a wide array of undergraduate students are not widespread in the liberal arts college environment. There are many reasons for this, ranging from lack of faculty expertise, tools, and design spaces to philosophically-related suspicions that engineering is a theoretically impoverished and/or "too 
professional" field of study, as well as the idea that the everyday technological world as a whole does not warrant attention in the curriculum. But given the traditional mission of so many liberal arts colleges of preparing students for active lives as informed citizens, and the desire if not passion of so many liberal arts college students to change the world and improve the quality of human life, the lack of such introductory courses is evidence of a lingering, and troublesome, blind spot in the liberal arts college environment.

In this paper, we - one of us a mathematician with a background in engineering and the other a philosopher with a background in philosophy of technology and philosophy of engineeringdescribe and reflect on our experiences in the Fall of 2016 team-teaching Thinking Like an Engineer, a course we developed for first year students at Macalester College as one contribution to countering this blind spot. In developing this course, our primary interest was to give students at an early stage in their academic experience an introduction to engineering, whether they came to college with the idea of possibly pursuing a career in engineering or whether they wanted to get a deeper understanding of the influence of engineering on the world in which they live. For that reason our orientation in this course was different from the orientation found in Bucciarelli's and Drew's proposal for integrating the liberal arts with engineering (2015). As we were not primarily interested in preparing future engineers, our course was less technically (mathematically) focused. Our course was also different from some of those just mentioned due to its "no-frills" nature with respect to resources: there were no design labs, maker spaces, or equipment available for our students to use. This was the challenging context within which Thinking Like an Engineer - both understanding what it means to think like an engineer, and gaining some practice in doing so - unfolded over the course of a semester.

Our paper will be divided into three parts. In the first part (Section Two), we will outline the learning objectives that we set out for our students and show how these objectives were reflected in the course design, particularly with respect the choice of topics, reading materials, and design activities. Following that (in Section Three), we will turn to look at the results of quantitative and qualitative assessments done in conjunction with the course, including a pre- and post- test measuring degree of confidence in carrying out different tasks within the engineering design process. Our thoughts wrap up in Section Four with a discussion of what was learned from teaching this course together, and how what was learned adds to the idea that engineering belongs among the disciplines of the liberal arts.

Part Two: the design, structure, and content of Thinking Like an Engineer

Macalester College is a private, BA-granting only, liberal arts college located in the upper Midwest with a student body of slightly more than 2100 students. As is typical for many liberal arts colleges, all first year students are required to take a designated first year course, generally with an enrollment of sixteen students, for the purpose of helping them in the transition from high school to college-level work: for example, it is mandatory to schedule one course meeting in the library where students get a hands-on introduction to the library's print and electronic 
resources. At Macalester, it is also typical for each department to offer at least one first year course (FYC), either an introductory level course already included in the curriculum or a new course offering. Incoming students do not sign up for these courses themselves, but are enrolled by the Registrar based on expressed student preferences. In addition, any faculty member teaching a FYC can decide whether the course should be residential, meaning that the students in the course live on the same floors in a residence hall, or non-residential in character. Instructors also have discretion as to whether to propose their FYC to count toward the college's threecourse graduation requirement in writing.

In putting together Thinking Like an Engineer as a first-year course, the primary learning goal we had in mind was to counter the stereotype that engineering was a field of inquiry whose dynamics mainly stemmed from the application of technical knowledge drawn from the fields of mathematics and the natural sciences. We were interested in getting students to see engineering as evolving and interdisciplinary, as a field within the liberal arts (as noted in the remark by Carol Christ in the previous section) that draws upon different kinds of knowledge and skills in order to address complex, contemporary problems such as the Grand Challenges identified by the US National Academy of Engineering. In particular, given our own specific types of expertise, we wanted students to come to appreciate that good engineering thinking, from the get-go, involves thinking about the ethical implications of what is being designed, rather than designing first and thinking about the ethical implications afterward. We wanted the course to afford an opportunity to students to come to have an appreciation of the similarities as well as the differences between engineering problem-solving and problem-solving in philosophy. We also wanted students to appreciate the extent to which engineering design is increasingly done in contexts marked by uncertainty and risk. Beyond these objectives, we were also hoping that we would be able to "model" respectful understanding for one another's disciplines, and so to try to head off at the pass, in the undergraduate experience of these students, the all too common vision of the liberal arts as divided into spheres of "hard" and "soft" thinking.

Our interest in these learning objectives influenced the decisions we ended up making about the course in a variety of ways. For one, we requested that the enrollment in the course be evenly divided among students who gravitated toward science and mathematics but who also had interest in philosophy and the humanities, and vice-versa. We also decided to make the course a residential course, so that students could talk to one another easily and be able to have a place to get together informally, in the absence of a design space or engineering lab, in order to collaborate on their design projects. How students responded to these decisions, as shown by comments on the course evaluation form, will be discussed later in this paper.

Secondly, these objectives became the basis for decision-making regarding the overall trajectory for the course and course assignments. As mentioned earlier, from the beginning, our primary challenge was: How could we best give students both a general understanding of what it is to think like an engineer as well as actual practice in thinking like an engineer-that is, in designing - in a "no frills" environment where we did not have additional resources at our 
disposal for students to design things and no "maker" space on campus within which they could work? But because our objectives were related to thinking like an engineer - in other words, to the process rather than the products of thinking - we were able to mitigate the disadvantages of what initially appeared to be a constraint and turn it into something that while not quite a virtue was able to take on a more positive cast.

In mapping our objectives in the context of our overall challenge onto the overall trajectory of the course and course assignments, we considered the idea of focusing it on the NAE Grand Challenges. Since there are fourteen Grand Challenges and just about that many weeks in a semester, in principle this could have worked well. But even though the Grand Challenges are vivid illustrations of how engineering problems and their solutions have social-political-ethical dimensions, we concluded that it would be a better idea, in terms of discussing engineered products, to start from the ordinary and the mundane, and expand from there. It is here how Henry Petroski's reflections on the paper clip in Invention by Design and Mark Miodownick's chapter on plastic from Stuff Matters entered the course syllabus. The order of design projects worked the same centrifugal way, as we started with a "solar hack" project on which students worked individually, and ended with a larger scale project in which students worked in teams organized to imitate how engineering teams are put together in the real world. While we did deliberately introduce ethical theory in the form of Mill's utilitarianism and Kant's ethics of duty fairly early on in the course, for the most part we interwove discussion about engineered objects with their ethical, social, and political dimensions.

And so, by the beginning of the fourth week of the course, students had read work by the philosopher Ortega y Gasset and the engineer Eugene Ferguson. They had thought about the differences and the similarities in problem solving among engineering, the studio arts, and philosophy. They had read one article by the philosopher Joe Pitt on the similarities of doing engineering to doing philosophy (think feedback loops), and another by the engineer William Bulleit, who writes about pragmatism, risk, and non-prototypical engineered systems. They were introduced to the engineering design process and, in reading some selections from Mill's Utilitarianism, had an opportunity to think about the connection between utilitarian thinking and cost-benefit analysis, which historically were developed at approximately the same time. And, as part of our efforts to get outside of our own "expertise bubbles" they heard one of us (the philosopher) introduce the article by the engineer and the other of us (the mathematician) do the same for the paper by the philosopher. Later on, the students heard the second instructor comment on the ethical issues associated with the gendering of technologies, and the first instructor explain why lithium-ion batteries in mobile phones are more susceptible to exploding than ordinary alkaline batteries.

The four student design projects in the course, influenced by our objectives and our budgetary constraints, also emphasized the process of thinking over the designed object. As mentioned just above, for the first project, the only materials-required design project of the four, students were asked to individually "re-purpose" a solar garden light for some other purpose than to light up a 
walkway. They were encouraged to use materials from a solar kit that they were required to purchase, from a solar garden light purchased by one of us out-of-pocket, and from whatever else they had at hand to use. They could also purchase materials up to a spending limit of ten dollars each. In the second project, students worked in pairs to create a design for an eating or a serving utensil that was intended to improve some aspect of human health (say by making it easier or more convenient to eat particular healthy foods) and/or to contribute to environmental sustainability. For this project, they did not have to give their design material form. Instead, they had to present it in the form of a shortened patent application, which needed to include two drawings illustrative of their invention.

On the third project, student teams of four served as "consultants" to peer "clients" in a FYC at Oberlin College on creativity, innovation, and design taught by Biology professor Taylor Allen. Following up on prototypes developed by the Oberlin student teams of shelters designed to meet the needs of feral cats during the winter, the Macalester "consultants" discussed with their Oberlin "clients" how solar elements could be added to the structures. The two sets of teams communicated with one another over e-mail, and the final "product" from the Macalester students was a YouTube video illustrating how the solar element could be included.

The fourth and final design project also saw our students working together in teams of four, playing the roles of project manager and sub-project managers, as they took an idea through the steps of the design process for an innovation that could hypothetically be integrated into the Macalester campus. The project's end result was a model or mock-up of the design. As for each of the other projects, students made oral presentations to the class. In these particular presentations and in a reflective paper connected to it, students reflected on costs and trade-offs, as well as how their ideas developed and were modified as a result of preliminary feedback.

One final point before turning to look at what was learned from student assessment of the course. Along with this reflection paper and two papers focused on sharpening students' capabilities for argumentative writing, we also asked students to write brief essays on a weekly basis, sometimes in class, sometimes as take-home assignments. These assignments, also oriented toward giving students more practice in argumentative writing, were not free-writes, as prompts were given on every occasion. But, they were oriented toward giving students an opportunity to think freely and imaginatively, and by way of this gain some insight into the importance of imagination in engineering thinking. Questions on which to write included "What would be the best sound for an electric car to emit to let pedestrians know it was coming?" and "If you could re-design yourself to have a superpower, what would that superpower be?".

Section three: assessment

We have three types of assessment of Thinking Like an Engineer: a pre/post class survey, an end of course survey, and (although not a formal assessment) a final writing assignment. So we have both qualitative and quantitative assessments. 


\section{[1] Pre/Post Survey}

Because one of our design projects linked our students with the students from one of Taylor Allen's classes at Oberlin College, we decided to use the same three pre and post-course surveys that he had chosen. They were:

1. The Student Understanding of Science and Scientific Inquiry Questionnaire (SUSSI) (Liang et al, 2008). We administered the eight survey questions from the two parts on "social and cultural influence on science" and "imagination and creativity in scientific investigations."

2. The Views on Science-Technology Society Questionnaire (VOSTS) (Aikenhead and Ryan, 1992). We administered five questions on the nature of science.

3. The Engineering Design Self-Efficacy Instrument (Carberry et al, 2010). We administered eight questions on engineering design and its sub-steps.

We have not completed our analysis of the data, but will mention a few preliminary findings.

1. The Wilcoxon signed rank test with continuity correction for paired data does NOT show evidence that there is a statistically significant difference between pre and post test results for any of the eight questions on the SUSSI. We used the Wilcoxon test because we have paired data but were not comfortable assuming that the differences between pre and post test scores are normally distributed.

2. The Wilcoxon signed rank test with continuity correction for paired data does NOT show evidence that there is a statistically significant difference between pre and post test results for four of the five questions of the VOSTS. There was a difference (2-sided test) on our question 2 which is to select one of eight sentences that basically represents the student position with respect to the statement "The best scientists are always very open-minded, logical, unbiased and objective in their work. These personal characteristics are needed for doing the best science."

3. We did detect pre and post test differences in student responses to the Engineering Design Self-Efficacy Instrument. We want to describe this test in detail.

Among the explicit goals of the course were to help the students acquire an increased understanding of:

- what it means to "think like an engineer" and how this thinking is similar to/different from other kinds of technical and creative reflection;

- the engineering design process and key concepts of engineering design 
It is difficult if not impossible to measure student understanding, but we did attempt to get a sense of student self-assessments of design ability via the Engineering Design Self-Efficacy Instrument that surveyed their degree of confidence to perform each of the following eight tasks:

1. conduct a design project

2. define a design problem

3. gather information on the problem

4. generate ideas to solve the problem

5. invent what doesn't exist

6. identify optimal solution

7. prototype (i.e. draft) and refine (i.e. revise) the solution

8. communicate the solution's design

Students rated their confidence from 0 (cannot do at all) to 100 (certainly can do). Thirteen students completed both pre and post course surveys. The data show that student confidence increased for all eight activities. This conclusion is based on a nonparametric sign test. For each of the eight tasks, at least ten of the thirteen students indicated a higher level of confidence at the conclusion of the course. No students indicated a decrease in confidence on any of the first four tasks, and no more than two showed decreased confidence on any of the last four tasks.

All post-course mean confidence levels were 82.3 or higher, except for task 5 , to invent what doesn't exist, which was 69.1. Perhaps the low level of confidence concerning task 5 is itself an indication of a good appreciation of the engineering process. One of the themes of the course is the way in which engineers build on what has gone before rather than starting from scratch to invent something entirely new. Indeed, in the wrap-up discussion on the last class day one student explicitly mentioned as remarkable the incremental nature of engineering progress as opposed to a process that always begins with a clean slate.

[2] end of course survey

As is required for all courses at Macalester College, we conducted an end-of-course student evaluation. It had both quantitative and qualitative parts to it. We would like to mention just a few things from the evaluation that stood out for us.

We asked about the teamwork aspect of some of the projects. About half the students had only good things to say about the benefits of collaboration. Quite a few acknowledged the difficulty of working in teams. Eighty five percent of them specifically stated that living together was extremely helpful when it came project time. Our choice to make this course residential definitely met with widespread student approval. 
We asked the students to name their most and least favorite topics of the course. More students by far, nearly half, cited human enhancement, or re-engineering the human body, as most interesting. This topic perhaps more than any bridged the gap between the hard side of engineering and the ethics of doing the possible. Leaving reference to this topic aside, the lists of most favorite topics were nearly equally divided between engineering case studies and more traditional humanities topics. The students did report in great numbers that they enjoyed the interdisciplinary nature of the course.

In a more quantitative vein, the student were asked to rate on a scale of 1 to 5 how well the course met its objective of "Making you aware of the engineering design process and key concepts of engineering design." The average rating was 3.85 .

[3] final writing assignment

Perhaps the most interesting feedback from the students comes from the final short writing assignment in which they were free to choose aspects of the course that seemed most important to them. Their writing prompt was:

"How has your thinking about what it means to "think like an engineer" changed after this course?"

Two themes that stood out in these essays are the role of ethics in engineering practice and the complexity of engineering thinking. These themes suggest some success with one of our explicit course learning goals: To help the students acquire an increased understanding of how technical and social/political/ethical perspectives are joined together in engineering problem framing and problem solving.

The collection of student comments referring to ethics was found to be inspiring. The one of us with an engineering background recalls that during four years earning an undergraduate engineering degree many years ago ethics training occupied only about ten minutes of one class period and was not a topic on which one was examined. We believe that ethics should be on an engineering student's mind from the first day they begin their education. Here is a selection from the student papers.

"Before I just thought of engineering as problem solving. Ethics never even crossed my mind. ... Now I see that there is more to it than just technical problem solving."

"I did not realize how conscious engineers need to be about the implications of their designs to prevent dangerous and unjust situations from arising." 
"This course helped me understand that engineering is hard not only because you need to be proficient in math and drawing but also in ethical reasoning and thinking ahead."

Especially gratifying is this statement from the class cynic.

"I learned there are many engineers who hold themselves to a higher ethical standard than I expected. ... Enough do to make a difference."

Many of our students had imagined that doing engineering is a lot like working individually to solve a problem set from a math or science class. Probably many engineering students think the same thing, since traditional engineering education primarily consists of solving such problem sets until the final year design project. We hoped the students would gain from our course a more realistic picture of the engineering design process as it is in the real world. The explicit learning goal is to help the students acquire an increased understanding of the engineering design process and key concepts of engineering design. Our course worked toward this objective by not including any problem sets at all. They were replaced by discussion of the process via case studies and practice of the process through four low-budget design projects. Here is a sampling of student comments on the complexity of engineering thinking.

"I have learned that the problems engineers are asked to solve don't have perfect solutions, forcing them to approach these problems from many different sides."

"I realize that engineering is a lot more about design and teamwork than I had originally expected, and our design projects really brought that point home."

"I learned that the process of thinking is much more complicated than it seems."

“Originally, I thought engineering was all about creating a final product. I never contemplated the social and political feedback loops that can drastically change a design. Furthermore it is foolish to think that any design is final. ... To think like an engineer is not to conceptualize the perfect commercial product. To think like an engineer is to think like a philosopher, an artist, a mathematician, a scientist, and a politician all at the same time."

Our favorite line from the essays conveys perfectly what we hope all our students gained from the course:

"The most interesting view I have gained through this semester is, I think there is a little engineer within us all."

Section four: final thoughts 
In this section of the paper, we want to share some of our preliminary conclusions as we look back over Thinking Like an Engineer.

In a thorough and highly illuminating paper published by the National Academies on the value to be gained from looking at inquiry in STEM, the arts, and the humanities as being complementary to one another and mutually enriching (Stewart-Gambino and Rossmann, 2015), the authors note that STEM education for non-STEM students has often been framed as being valuable for improving their skills as engaged citizens, policy-makers, or managers (p.9), and that humanities and arts education for STEM students has traditionally been approached from the perspective of "topping off" what STEM students know so that they can better understand its real-world implications. While echoing the idea that these disciplines are more complementary to one another than often imagined, our course takes this idea a step further in two ways. It provides some admittedly small but not insignificant evidence that this complementarity can be augmented by not only combining course content and perspectives from the humanities and the sciences/engineering into a single course, but by having a course team-taught by faculty members from both areas of inquiry and with students in the class likewise having a broad representation of academic interests.

In short, every aspect of this course was a mix of two components still frequently imagined to be distinct. While many courses at liberal arts colleges offer courses where both STEM students and humanities or arts students are enrolled; rarely do these courses offer an opportunity for these students to interact closely and collaborate with one another in the classroom. Readings in philosophy and case studies in engineering rarely share the stage; the two teachers, a philosopher and a mathematician, rarely teach in the same building. We did not know when we started how this amalgam would work out. But all of us involved in the course share a common humanity, and that was more than enough to bridge the supposed divides. Few individuals are so specialized that they cannot find a connection to almost any human activity, whether it be philosophy or engineering design. At our core, humans are problem solvers and social beings, which makes us both engineers and ethicists throughout our lives. We found it refreshing to acknowledge this through the teaching we did together.

One initial concern we had was the lack of budget and experience to mount a large scale design project to be carried through to the construction of a product. We made do with very "no frills" virtual projects that, taken together, included many of the aspects of a real design project: design process including project management, feedback loops, budget analysis, ethical considerations, teamwork, and communication in a variety of forms. Though the projects were virtual, the evidence presented in the previous section, particularly with respect to the pre/post test assessment of confidence levels in the aspects of the standard engineering design process, allows us to reasonably conclude that students learned from these projects anyway and got out of the course much of what we wanted them to get out of it. More research would need to be done to 
see what the limitations of this approach might be: in other words, just how much students could learn about "liberal arts infused engineering" by becoming familiar with engineering processes of thinking without this familiarity being grounded in the design of actual objects themselves.

This points to how our course also underscores another idea explored by Stewart-Gambino and Rossmann (2015), namely that one place where the complementarity of the humanities, arts, and the STEM disciplines is most visible is in the engineering design process itself. As they observe:

The engineering design process synthesizes humanistic, social, creative, and analytical skills, and is thus one logical forum for meaningful integration of a range of disciplinary methods and values....While this is an engineering methodology, it shares with the arts an emphasis on creativity, and with the humanities and social sciences a comfort with the ambiguity of non-unique, context-specific solutions (p.13).

Reflecting on the positive changes in the degree-of-confidence scores described in the previous session leads to one of two questions which could serve as a basis for additional testing and research. First, Carberry, Lee and Ohland note (2010, p.74) a number of sources referring to "gender's known influence on the self-efficacy of engineering students." Marra et. al. (2009, p.27) indicate that "correlations show that self-efficacy is related to women's student's plans to persist in this predominately male discipline." We have not yet commented on the gender balance in the class, but of the sixteen students enrolled in the course, eleven of them were women. We did not notice differences in ability or interest in the course based on gender. While the self-assessments of ability to perform various engineering design tasks were answered anonymously, the sheer numbers suggest that women and men both increased in confidence during the course. This leads us to wonder what the impact is upon women students' interest in an engineering career from taking a course such as ours, compared to the impact upon women's students' interest in an engineering career where the outcomes of the design process are more tangible.

A second line of research may also be suggested by our course. It has been shown that engineering students have difficulty connecting the dots between what they learn about ethical theory in their classes and engineering design problems (for example, see Michelfelder and Jones, 2016). There is some debate within the engineering community as to whether or not ethics is best presented through case studies or as ethical theory. Does emphasizing the process of thinking like an engineer over the products of engineering thinking, in a course that affords many opportunities for students of diverse academic interests to engage with one another in a respectful manner, make connecting these dots less difficult?

In addition, one of the advantages of teaching a course such as ours in a liberal arts environment rather than an engineering school is precisely this ability to enroll a larger fraction of women. 
This offers an additional reason to believe that engineering in some form belongs in the liberal arts.

While students did not seem to differ much by gender with respect to degree of confidence, there were differences among students in general with respect to outlook, since some were contemplating STEM majors and others were not. This sometimes colored how they viewed the course. We heard comments from a couple of students that there were too many days devoted to engineering topics, yet some other students thought there was too much attention to philosophy. We like to think that this means we managed to give real weight to both sets of topics.

Finally, let us close by mentioning how much fun the course was to teach. The variety of students and the variety of topics, about half of which were new classroom experiences for both of us, kept this course interesting and stimulating from beginning to end. If our course could help to inspire other faculty at liberal arts colleges without formal engineering programs who are interested in exposing students to engineering inquiry, whether they be first year students or ones at a more advanced level, and who also would like to take advantage of the fact that thinking of the sort around which we constructed this course is, thankfully, a low-budget enterprise, we hope that they would have fun as well.

\section{References}

Aikenhead, G. S. and A. G. Ryan. 1992. "The Development of a New Instrument: 'Views on Science-Technology-Society (VOSTS)'. Science Education 76: 477-491.

Bucciarelli, L.L. and D. Drew. 2015. "Liberal Studies in Engineering: A Design Plan." Engineering Studies 7(2-3), 103-122.

Carberry, A.R., H.S. Lee, and M. W. Ohland. January 2010. "Measuring engineering design self-efficacy." Journal of Engineering Education 99(1): 71-79.

Christ, C. T. 2010. “What is Happening in Liberal Education?" In Holistic Engineering Education: Beyond Technology. Eds. Dominico Grasso and Melody Burkins. Dordrecht: Springer Press, 69-80.

Duderstadt, J. J. 2010. “Engineering for a Changing World.” In Holistic Engineering Education: Beyond Technology. Eds. Dominico Grasso and Melody Burkins. Dordrecht: Springer Press, 1736.

"Engineering-Enhanced Liberal Education Project", online at https://www.asee.org/engineeringenhanced-liberal-education-project/case-studies 
Liang, L. L. et. al. June 2008. "Assessing preservice elementary teachers' views on the nature of scientific knowledge: A dual-response instrument." Asia-Pacific Forum on Science Learning and Teaching 9 (1): Article 1.

Marra, R. M. et. al. January 2009. "Women Engineering Students and Self-Efficacy: A MultiYear, Multi-Institution Study of Women Engineering Student Self-Efficacy." Journal of Engineering Education 98(1): 27-38.

Stewart-Gambino, H. and J. S. Rossmann. 2015. "Often Asserted, Rarely Measured: The Value of Integrating Humanities, STEM, and Arts in Undergraduate Learning." National Academies of Sciences, Engineering and Medicine.

Michelfelder, D. and S. A. Jones. "From Caring About Sustainability to Developing Care-Ful Engineers." 2016. In New Developments in Engineering Education for Sustainable Development. Eds. Walter Leal Filho and Susan Nesbit. Switzerland: Springer International Publishing, pp. 173-184. 